\title{
Modified Mortars with the Polymers Addition for Thermal Insulation Systems of Polystyrene
}

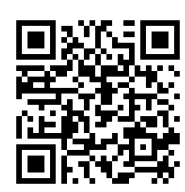

\author{
Krdžalić Edin*1,2 ${ }^{*}$ Halilović Namir ${ }^{2,3}$, Mujkanovic Adnan ${ }^{1}$ and Bašić-Halilović Azra ${ }^{4,5}$ \\ ${ }^{1}$ Faculty of Metallurgy and Materials Science, Department of Chemistry, University of Zenica, Bosnia and Herzegovina \\ ${ }^{2}$ KOMOCHEM, Bosnia and Herzegovina
}

${ }^{3}$ Faculty of Science, Department of Chemistry, University of Sarajevo, Bosnia and Herzegovina

${ }^{4}$ Faculty of Pharm and Health, University of Travnik, Bosnia and Herzegovina

${ }^{5}$ Institute for Biomedical Research and Diagnostics GENOM, Travnik

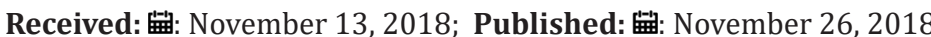

*Corresponding author: Krdžalić Edin, Faculty of Metallurgy and Materials Science, Department of Chemistry, KOMOCHEM, Bosnia and Herzegovina

\begin{abstract}
At the time of the increasing shortage of fossil fuels and their rising prices, energy saving is the main topic. For example, in Germany in the housing sector $75 \%$ of the total energy is consumed for the air conditioning in the household, mainly for heating. Today, all new buildings must meet the standards for energy efficiency. The fastest and most efficient way to save energy for heating and improving the climate inside the building is thermal insulation of external walls of the building. In this paper, polymer-cementitious adhesive for bonding and reinforcing, its composition, characteristics and mechanism of binding to the substrate was processed. The influence of the dispersed polymer on the characteristics of polymercement mortar for external thermal insulation has been examined in details.
\end{abstract}

Keywords: Redispersible Polymers; Polymer Cement Mortar; Polymer Cementitious Adhesive for Bonding and Reinforcing

Abbreviations: EPS: Expanded Polystyrene; PC: Portland Cement; PPC: Portland Pozzolanic Cement; HAC: High Alumina Cement; MC: Methyl Cellulose; MHEC: Methyl Hydroxyethyl Cellulose; MHPC: Methyl Hydroxypropyl Cellulose

\section{Introduction}

A typical system of external thermal insulation consists a polymer-cement adhesive for bonding of insulation material, insulation plates of expanded polystyrene (EPS) or stone wool, then polymer-cement base layer for mounting and reinforcing of facade mesh, fixing components (insulation wedges), one or more finishing layers of polymer-cement adhesive [1]. Components of external insulation system shown in Figure 1. A parameter that characterizes thermal losses through walls is the coefficient of thermal conductivity, This is the amount of heat the building element loses in one second per $\mathrm{m} 2$ surface at a temperature difference of $1 \mathrm{~K}$, expressed in $\mathrm{W} / \mathrm{m}^{2} \mathrm{~K}$. Lower coefficient of heat conductivity means better thermal protection of the building. The most desirable insulation material is stone wool because it is a good insulator and has the ability to diffuse vapor, and styrofoam is located on second place [2,3] (Figure 1).

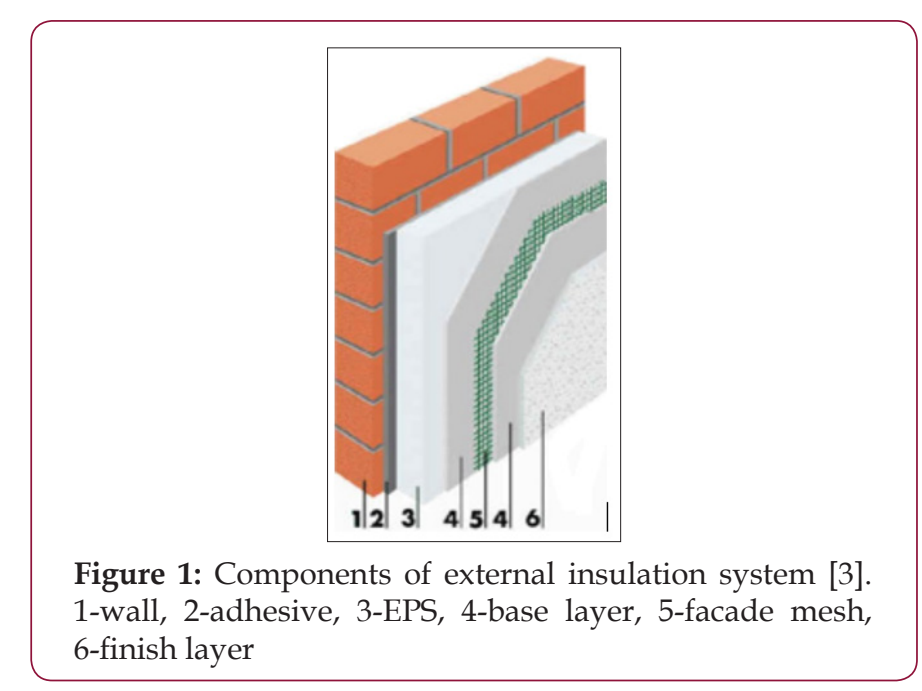




\section{Application of Polymer-Cement Adhesive}

The first discovery is the development of a powdery redisperse polymer. The polymers added to cement-based adhesives to improve their elasticity and adhesion to the substrate. With the advent of this technology allows the construction chemical industry to present dry polymer-modified adhesives for a variety of purposes:Adhesives based on ceramic bonding cement,

a) Mortars based on gypsum or cement,

b) Cementitious adhesives for thermal insulation,

c) Grout mass,

d) Self-healing mass,

e) Repair mortars,

f) Mortar for masonry,

g) Cementitious waterproofing

Today's dry polymer-cement adhesives contain numerous additives to improve applicability (open time, consistency, etc.) as well as bonding to the substrate (water retention, elasticity). As the production process is automated and computer controlled, products are produced of precisely defined and uniform quality as well as precisely defined properties with a high degree of reliability in application [1]. When installing an external thermal insulation system, two types of adhesive are required:

A. Adhesive for bonding insulating material to a concrete wall or brick wall (good adhesion to the wall and insulation material as well as good flexibility to handle different coefficients of thermal expansion of the substrate).

B. Adhesive for reinforcement. It should cover the insulation material and to form the base wear-resistant layer for decorative plaster. The reinforcement adhesive requirements are slightly different from the adhesive bonding requirements. Good adhesion to the insulation material, long open time, easy handling, good impact resistance and low water absorption are also important properties of reinforcement adhesives. It is often a compromise and the same material is used for bonding and for reinforcing.

\section{Connective Tissue}

The main tasks of the binder are to form a firm bond with the substrate and the material for thermal insulation (adhesion), as well as to link the aggregate grains (cohesion). Today, there are three main types of cement used in the polymer-cement based adhesives: Portland cement (PC), Portland Pozzolanic Cement (PPC) and aluminate cement (High Alumina Cement, HAC) [1]. Portland cement is a hydraulic binder that is obtained by fine grinding portland cement clinker with a specific addition of gypsum, which binds and cures in air and under water. The raw material for the production of portland cement consists of limestone and clay minerals, whereby this ratio is usually $75-80 \%$ limestone and 20 $25 \%$ clay minerals. The binding speed is regulated by adding $3-5 \%$ of the gypsum or anhydrite [4].

\section{Aggregates}

Generally, aggregates mean material loosening structures formed in the form of assemblies of more or less identical particles, i.e. material relatively homogeneous in the sense of substancebuilders. Aggregates contain unbound particles (granules) of a certain size. In the narrow sense, aggregates are all grainy (inert) materials that, together with certain bonding materials (cement, lime, bitumen, polymers), are used to obtain various types of mortar and concrete, therefore, materials that are defined by the general term composite materials. Generally, aggregates are classified as natural or artificial [5,6]. In this paper, two natural, inorganic aggregates, ie quartz sand, particle size up to $0.8 \mathrm{~mm}$, and stone dust (so-called filler) were used, particle size up to $0.1 \mathrm{~mm}$. Thus, in this case, a combination of aggregates of different particle sizes is used to ensure a better packing, where smaller particles fill the vacuums between larger particles.

\section{Additives}

Additives are substances usually of organic origin, which are added in small amounts to a dry mix, modifying the properties of fresh or hardened glue, mortar or paste. The content of these supplements is usually below $1 \%$. Only redisperse polymers are added in higher percentages. Additives for the production of dry mortar may be added to the mixture solely in powder form. If several different accessories are used, they must be compatible with each other.

\section{Redispersible Polymers}

Redispersible polymers are organic polymeric materials produced from aqueous dispersions by spraying technology, as shown in Figure 2. Water dispersions are two-phase systems in which the dispersant is water. Redispersible polymers provide the following properties in adhesives for thermal insulation:

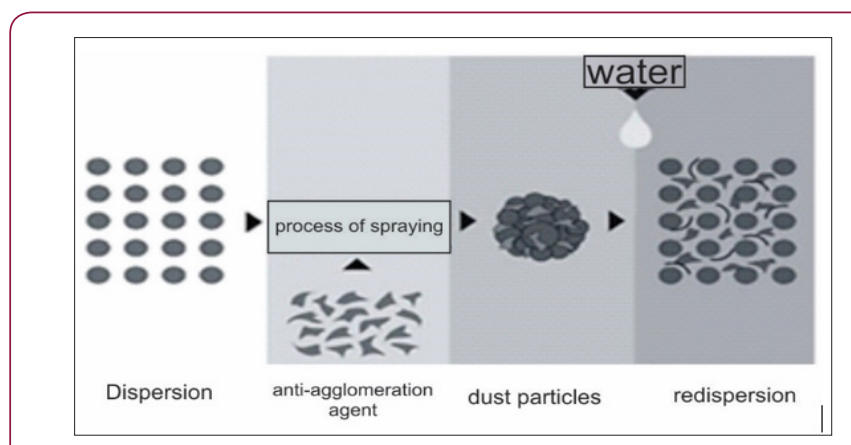

Figure 2: Simplified process of forming redispersible polymers and forming redispersion [6].

The synthetic polymer is dispersed in water.

a) Better adhesion to the substrate,

b) Impact resistance

c) Less damage during impact,

d) Aging properties (good properties after varying climatic conditions), 


\section{e) Hydrophobicity (good water odor).}

Dosing of redispersible polymers ranges from 0 to $5 \%$, but it should be noted that the overall product price increases with increasing polymer content so that the content of the polymer needs to be accurate enough to achieve satisfactory results as far as the characteristics of the final product are concerned. The following picture shows the structures of the most commonly used polymer in adhesives for external thermal insulation systems [1] (Figure 3).

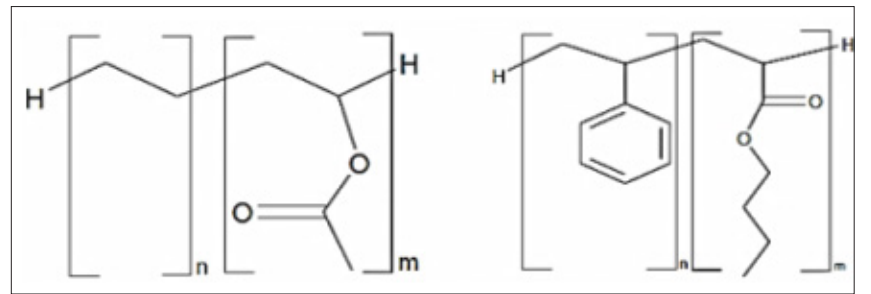

Figure 3: Copolymer structures of ethylene-vinyl acetate (left) and styrene-butyl acrylate (right) [1].

\section{Water Retention Additives}

The main purpose of the water retention additive is to keep the water in the fresh adhesive for a longer period of time so that the cement has enough available hydration water. Water also acts as a lubricant to improve the freshness of fresh adhesives and is also essential for the hydration process of cement. The loss of water from the adhesive is reduced by the adsorption of waterretaining additives on the substrate and on the bonding particles and by forming a thin layer of low permeability. Other parameters influenced by water retention additives are open time, improved wettability of the particles, and reduced subsidence of the adhesive. High water retention can be achieved by chemically modified methyl cellulose (MC). Methyl cellulose modification is performed with ethylene oxide or propylene oxide. The resulting modification products are methyl hydroxyethyl cellulose (MHEC) having the structure shown in (Figure 4) or methyl hydroxypropyl cellulose (MHPC). The MHEC content in formulations does not exceed values greater than $0.5 \%$. The following illustrations show the solubility of MHEC and MC with increasing temperature and retaining water with the addition of MHEC (Figures $5 \& 6$ ).

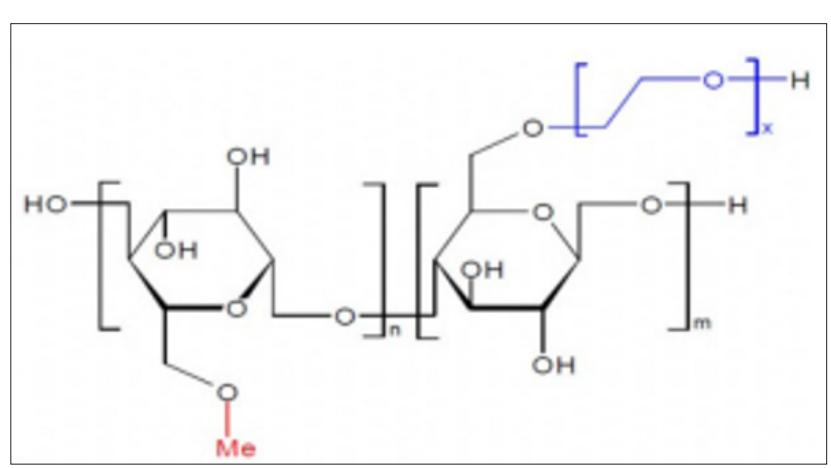

Figure 4: Structure of methyl hydroxyethyl cellulose (MHEC) [1].

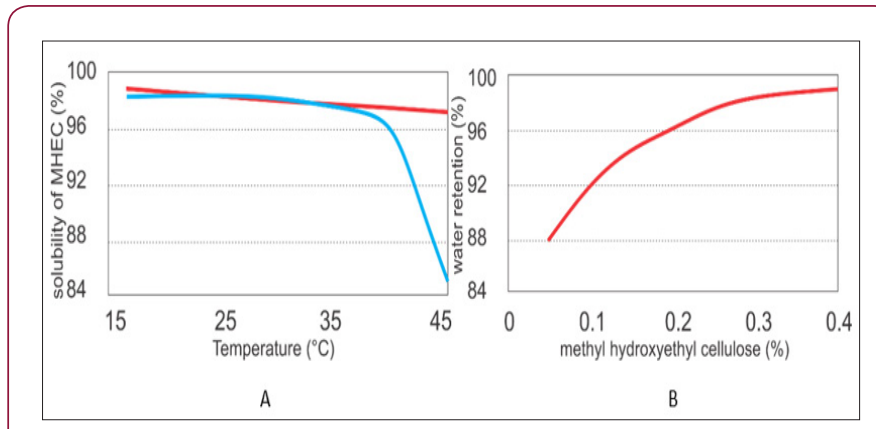

Figure 5: a) Solubility of MC and MHEC, b) Water retention as function of MHEC addition [1].

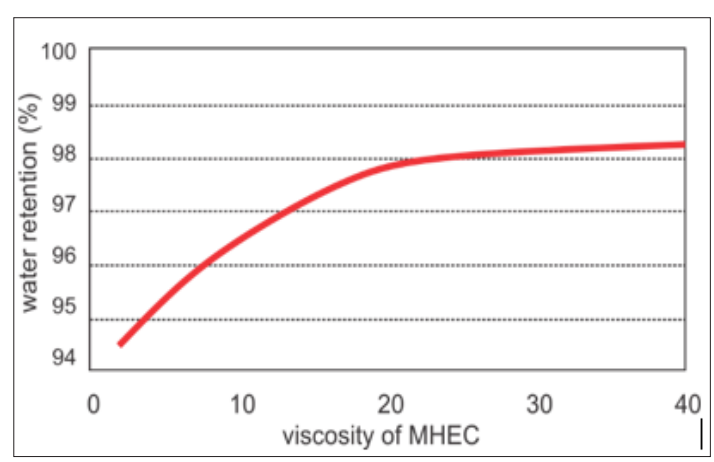

Figure 6: Water retention of fresh mortar as a function of viscosity MHEC [1].

\section{Accelerators}

Accelerators are generally used in colder conditions, to accelerate bonding and increase the early strength of the adhesive. Calcium chloride, calcium formate or lithium carbonate are commercially available accelerators. Typical amounts of these supplements are about $0.5 \%$ [1].

\section{The Formulations of Polymer Cement Adhesive for Thermal Insulation}

Table 1: Example of recepture for polymer-cement adhesive for bonding of EPS [6].

\begin{tabular}{|c|c|c|c|}
\hline & Component & Function & [\%] \\
\hline 1. & Cement & Binder & $33,00-35,00$ \\
\hline 2. & $\begin{array}{c}\text { Quartz sand } \\
0,1-0,8\end{array}$ & Filler & $35,00-37,00$ \\
\hline 3. & $\begin{array}{c}\text { Stone dust } \\
0-0,1\end{array}$ & Filler & $25,00-28,00$ \\
\hline 4. & $\begin{array}{c}\text { Redispersible } \\
\text { polymer }\end{array}$ & Flexibility / Adhesion & $1,00-1,50$ \\
\hline 5. & MHEC & Workability & do 0,25 \\
\hline
\end{tabular}

Typical adhesive formulations for EPS bonding, then adhesives for reinforcing facade mesh, are shown in Tables $1 \& 2$. As the adhesive for EPS plate can only be used for this purpose, the adhesive that is used for reinforcement, also may be used for bonding EPS plates, but this is rarely done for economic reasons, ie. adhesive for reinforcement has a higher price. The main difference between adhesives for EPS bonding and reinforcement adhesives 
is in the content of redisperse polymers. Reinforcement adhesive has a higher proportion of redisperznog polymer. Of course, these formulations are rough guidelines because the raw materials differ from the manufacturer to the manufacturer.

Table 2: Example of recepture for polymer-cement reinforcement adhesive [6].

\begin{tabular}{|c|c|c|c|}
\hline & Component & Function & [\%] \\
\hline 1. & Cement & Binder & $33,00-35,00$ \\
\hline 2. & $\begin{array}{c}\text { Quartz sand } \\
0,1-0,8\end{array}$ & Filler & $35,00-37,00$ \\
\hline 3. & $\begin{array}{c}\text { Stone dust } \\
0-0,1\end{array}$ & Flexibility / Adhesion & $23,00-26,00$ \\
\hline 4. & Redispersible polymer & Flexibility / Adhesion & $2,00-3,00$ \\
\hline 5. & MHEC & Workability & until 0,25 \\
\hline
\end{tabular}

\section{Adhesive Bonding Mechanism}

Table 3: The basic ingredients of portland cement.

\begin{tabular}{|c|c|}
\hline Component & Mass. \% \\
\hline$\left(3 \mathrm{CaO} \cdot \mathrm{SiO}_{2}\right), \mathrm{C}_{3} \mathrm{~S}$ (alit) & $45-60$ \\
\hline$\left(2 \mathrm{CaO} \cdot \mathrm{SiO}_{2}\right), \mathrm{C}_{2} \mathrm{~S}$ (belit) & $20-30$ \\
\hline$\left(3 \mathrm{CaO} \cdot \mathrm{Al}_{2} \mathrm{O}_{3}\right), \mathrm{C}_{3} \mathrm{~A}$ & $4-12$ \\
\hline$\left(4 \mathrm{CaO} \cdot \mathrm{Al}_{2} \mathrm{O}_{3} \cdot \mathrm{Fe}_{2} \mathrm{O}_{3}\right), \mathrm{C} 4 \mathrm{AF}$ & $10-20$ \\
\hline
\end{tabular}

Portland Cement Hydration: The basic ingredients of portland cement clinker are $\mathrm{CaO}(\mathrm{C}), \mathrm{SiO}_{2}(\mathrm{~S}), \mathrm{AI}_{2} \mathrm{O}_{3}(\mathrm{~A})$ i $\mathrm{Fe}_{2} \mathrm{O}_{3}(\mathrm{~F})$. These compounds do not appear in the cement as free, but they are always in the form of various complex compounds. The mineral composition of portland cement is shown in Table 3. The silicates and aluminates present in the cement react with water to form the appropriate hydrates and form a solid mass. $\mathrm{C}_{3} \mathrm{~S}$ hydrates very quickly and it is responsible for the initial strength of the cement, while on the other hand, the $\mathrm{C}_{2} \mathrm{~S}$ solidifies slower (Figure 7). Formation of the structure of hardened cement as a composite binder in the early hydration period, based on the given concept of hydration of the main or basic minerals from the cement clinker, can be schematically shown in (Figure 8). From this scheme, the basics of the hydration process and the development of the structure are realized. The reaction system from the fluid state, the "paste" state or suspension, passes to a new non-fluid state, a condition similar to a stone, with certain physico-chemical and mechanical properties. This approach makes it possible to explain the phenomenology of the transformation of a fluid cement paste into solid or solid cement stone-cement gel, and the formation of its structure as the basis for its stability and durability during use in practical application [7].

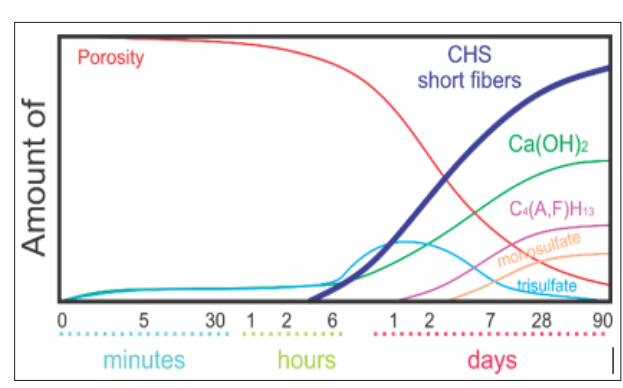

Figure 7: Schematic representation of the concentration of hydration products depending on the hydration time [4].

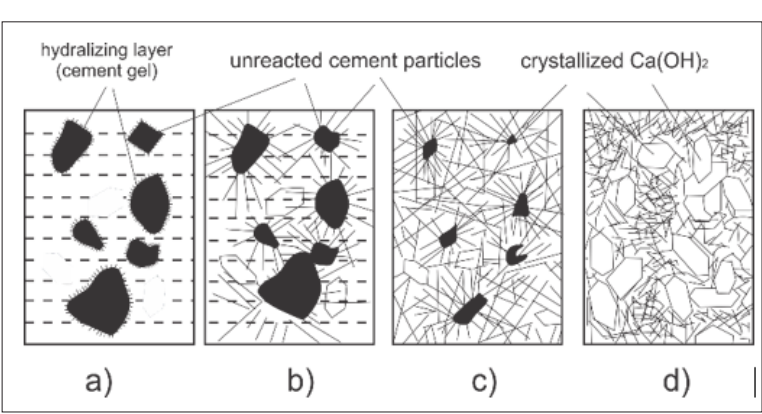

Figure 8: Schematic representation of the hardened cement paste structure a) the plastic phase b) the binding phase, c) the basic skeleton of the hardened paste, d) the "stable" skeleton of the hardened paste [7].

Formation of Polymer Film: The main mechanism by which the adhesive achieves its mechanical properties over time is the hydration of cement, and the auxiliary mechanism, which further enhances the properties, is the formation of polymer bonds by the polymer. The polymer film builds polymer bonds, which have a significant effect on the mechanical properties of the hardened adhesive. These properties depend on the type of redisperse polymer and the concentration of the polymer in the glue. The following figure shows the mechanism for forming a polymer film (Figure 9). It takes time and temperature to form polymer bonds in the cement matrix. When the EPS slabs are on the wall, the temperature must be above the MTFF of redispersion polymers (also during the night) and without precipitation for smooth film formation. After forming the polymer film, the film is no longer sensitive to moisture (except saponification).

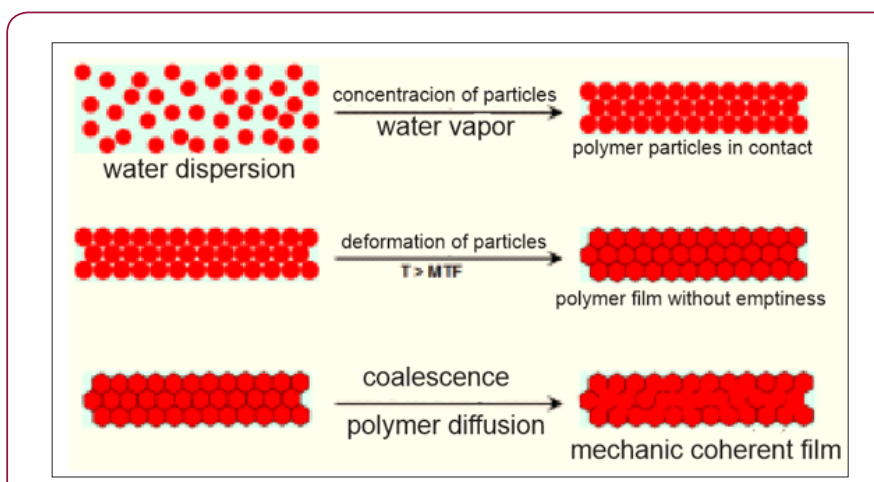

Figure 9: Mechanism for forming a polymer film [1].

A lower glass transition temperature means a softer, more flexible polymer. There is some discussion about when to use a softer polymer ( $\mathrm{Tg}<\mathrm{T}$ applications), and when the hard polymer (Tg > T applications). For example in water-resistant cementbased products, which need to provide flexibility and bonding to the substrate during winter and cold nights, redispersion polymers with $\mathrm{Tg}-15{ }^{\circ} \mathrm{C}$ are used, in the adhesives for ceramic tile $\mathrm{Tg}$ is about $+10{ }^{\circ} \mathrm{C}$. In adhesives for bonding EPS plates, polymers are generally used with $\mathrm{Tg}$ about $-6{ }^{\circ} \mathrm{C}$. The MTF of the redisperse polymers is from $0{ }^{\circ} \mathrm{C}$ to $5{ }^{\circ} \mathrm{C}$ (Figure 10 ). Polymer bonds improve the mechanical properties of hardened adhesive, i.e. elasticity and bonding of adhesives on the substrate and on the EPS board with 
polymer bridges. This is especially important in the case of a nonporous substrate because the mutual mechanical adhesion of low pores cement crystals is insufficient for immediate adhesion [1].

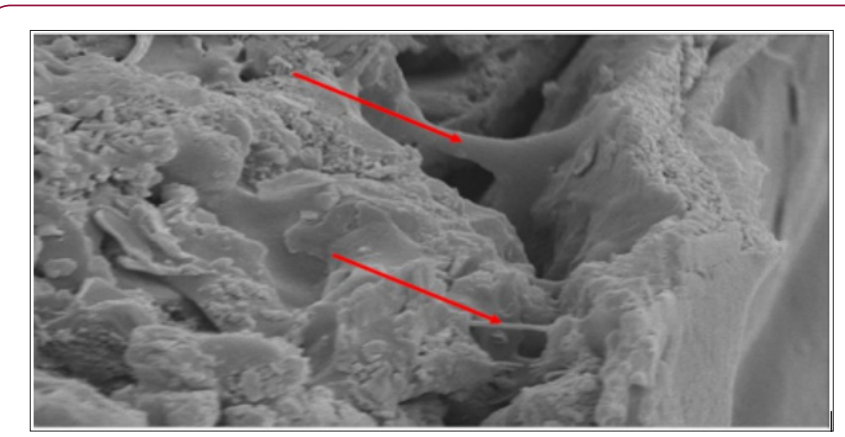

Figure 10: Microscopic recording of polymer bonds in a cement metric [3].

Influence of Temperature on Bonding of Glue: Thermoplastic polymers are semi-crystalline solids consisting of crystalline and amorphous parts. The ratio of crystalline and amorphous parts depends on the primary structure of the polymer and on the parameters of the production process. The amorphous parts of the solid polymer can be in glass or rubber, depending on the ambient temperature. The temperature at which the transformation from the glass state occurs to the rubber and vice versa is called the glass transition temperature ( $\mathrm{Tg}$ ). Below Tg polymers are rigid and fragile. By heating, they soften and become more elastic, i.e. they go into a rubbery state. Another parameter important for the formation of a polymer film is the minimum temperature of film forming (MTF). MTF is the temperature at which the polymer particles will coalesce and form a continuous unopened film. Therefore, it is the lowest temperature that is necessary to meet the conditions to start the formation of the film. The minimum temperature of the film formation depends on the size of the dispersion particles, the drying time, etc., but mainly depends on the glass transition temperature of the polymer. Polymer dispersions do not form a film at a temperature below the MTF, but only white powder is formed. The polymer dispersions that dry at a temperature slightly below the MTF form a white, opaque low-strength film. Just above the MTF deformation and coalescence of the dispersion particles is strong enough to form a continuous film without cracks. Socalled coalescing additives, plasticizers, solvents can lower the MTF far below the Tg of dry polymer. Thus, the choice of coalescing additives is an interesting field of investigation to ensure that polymer dispersions in adhesives form a film even when used at + $5^{\circ} \mathrm{C}$. Examples of coalescing additives are dibutylphthalate (DBF), ethylene glycol ethers and organic solvents (e.g., toluene). The MTFF polymer can be reduced by more than $20^{\circ} \mathrm{C}$ [1].

Stabilnost Prema Vodi: After the polymer diffused between adjacent particles, the formed polymer bonds are not soluble in water. However, the film still contains a water-soluble protective colloid that easily absorbs water so that the polymer bonds can hydrate and swell, which can weaken the adhesion strength of the hardened adhesive. Depending on the nature of the polymer, there is a possibility of reacting (saponification) (Figure 11). Poly (ethylene-vinyl acetate) hydrolyzed (saponified) in the presence of alkali in an alcohol and polyvinyl acetate. Alkalinity $(\mathrm{pH}>12)$ is present in cementitious adhesives when they come into contact with water. High alkalinity catalyzes EVA hydrolysis (Figure 12). Water solubility can be increased to the extent that the polymer can be washed out of the cement matrix by rain. Polymers containing nonpolar monomers (ethene, butadiene, styrene ...) are not susceptible to saponification [1].

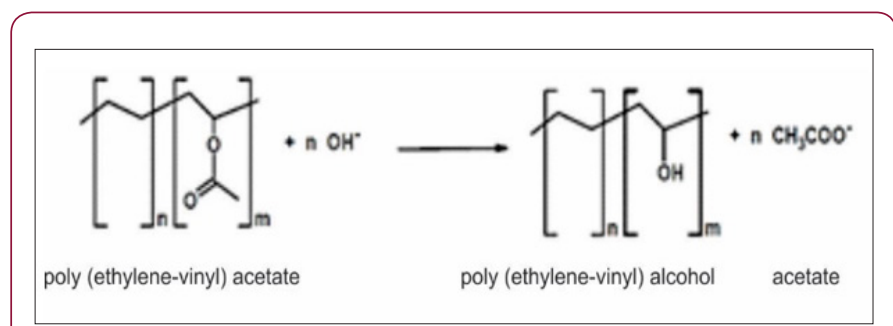

Figure 11: Polymers containing vinyl acetate (VA).

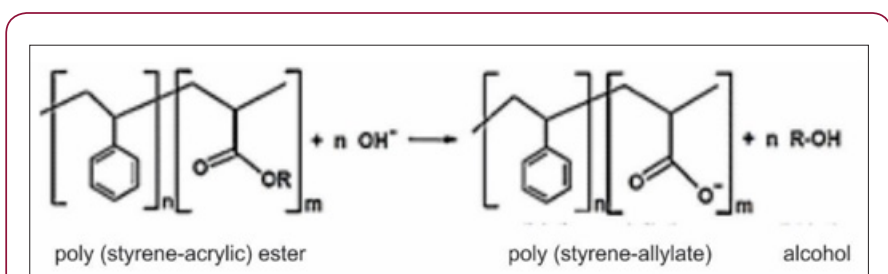

Figure 12: Polymers containing acrylate esters.

\section{Experiment}

We examined the characteristics of the adhesive depending on the share of the redispersion polymers in it:

a) Testing the consistency of fresh adhesive,

b) Testing the adhesion of adhesive to the surface

c) Testing bending strength of hardened adhesive,

d) Testing compressive strength of hardened adhesive,

e) Testing capillary water absorption of hardened adhesive

f) Testing the volume mass of hardened adhesive.

Test results are presented in tables and diagrams, along with photos of the samples and a short description of the test.

\section{Technical characteristics of the components for making the adhesives used in the practical part of the work}

Cement: As a cement binder in our experiments we used Portland cement with the addition of fly ash CEM II / B-W $42.5 \mathrm{~N}$, manufactured by Kakanj cement. Cement meets all the prescribed requirements and it is suitable for the preparation of adhesives for sticking EPS plates and adhesives for reinforcement. Additional testing of cement is not required. Proportion of cement in the formulations was $33.1 \%$. The chemical composition of Portland cement CEM II / B-W $42.5 \mathrm{~N}$ is shown in Table 4 [8]. Cement producer Kakanj cement is shown in Table 5. 
Table 4: The chemical composition of Portland cement CEM II / B-W 42.5 N [8].

\begin{tabular}{|c|c|c|c|c|c|c|c|c|c|c|}
\hline Oxides & $\mathbf{S i O}_{\mathbf{2}}$ & $\mathbf{A l}_{2} \mathbf{O}_{\mathbf{3}}$ & $\mathbf{F e}_{2} \mathbf{O}_{\mathbf{3}}$ & $\mathbf{C a O}$ & $\mathbf{M g O}$ & $\mathbf{S O}_{\mathbf{3}}$ & $\mathbf{N a}_{\mathbf{2}} \mathbf{O}$ & $\mathbf{K}_{\mathbf{2}} \mathbf{O}$ & $\mathbf{C a O}$ free & $\begin{array}{c}\text { Ignition } \\
\text { loss }\end{array}$ \\
\hline$\%$ & 20,02 & 3,98 & 3,46 & 65,36 & 1,48 & 2,61 & 0,07 & 0,55 & 1,88 & $\geq \% 5,0$ \\
\hline
\end{tabular}

Table 5: Mineralogical composition of portland CEM II/B-W $42,5 \mathrm{~N}[8]$.

\begin{tabular}{|c|c|}
\hline Mineral & \% \\
\hline $\mathrm{C}_{3} \mathrm{~S}$ & 68,95 \\
\hline $\mathrm{C}_{2} \mathrm{~S}$ & 15,85 \\
\hline $\mathrm{C}_{3} \mathrm{~A}+\mathrm{C}_{4} \mathrm{AF}$ & 15,20 \\
\hline
\end{tabular}

Water: Water for preparing of the glue is taken from the city water supply network. This is drinking water and can be used, without prior testing, for making adhesive for gluing EPS plates and reinforcement.

Aggregates: Aggregates used in the experiments are inorganic, natural aggregates of different particle size distribution and mineral composition, ie. quartz sand and stone dust, known as filler. The share of quartz sand amounted to $37.5 \%$, a stone dust (filler) from $30 \%$ to $35 \%$, depending on the share of redispersed polymer.

Additives: For the preparation of samples we used additives for water retention and redispersion polymers.

Redispersion polymers (RDP): Redispersion polymers are organic polymeric materials. These polymers are prepared from aqueous dispersions by diffuser technology. They have an influence on the properties of adhesives for external thermal insulation. Dispersible polymer that is used in preparing the samples is ethylene-vinyl acetate, and its commercial name is "Vinavil 5603 PB", Vinavil, manufacturers from Italy. The goal of this study was to examine the characteristics of adhesives for external thermal insulation, depending on the share of redispersed polymer. The share of the redispersed polymer in the samples was $0 \%$ ie. without RDP, $1 \%, 2 \%, 3 \%$ and $5 \%$. The characteristics of the used RDP are given in the following Table 6 [9].

Table 6: Technical specifications VINAVIL-a 5603 PB" [9].

\begin{tabular}{|c|c|}
\hline Moisture content, $\mathbf{m a x} \%$ & max. 1 \\
\hline Density on $23^{\circ} \mathrm{C}, \mathrm{kg} / \mathrm{dm}^{3}$ & $0,55 \pm 0,05$ \\
\hline Protective colloid & Polyvinyl alcohol \\
\hline Dush content, $\%$ & $12 \pm 2$ \\
\hline Residue on the sieve $>500 \mu \mathrm{m}, \%$ & $<0,5$ \\
\hline $\mathrm{Tg},{ }^{\circ} \mathrm{C}$ & -6 \\
\hline MTF $\left(50 \%\right.$ redispersion),${ }^{\circ} \mathrm{C}$ & 0 \\
\hline Viscosity by Brookfield & \\
\hline (50\% redispersion), $\mathrm{mPa} \cdot \mathrm{s}$ & $<1000$ \\
\hline $\mathrm{pH}$ value & $7,5 \pm 0,5$ \\
\hline
\end{tabular}

Modified methyl hydroxy ethyl cellulose is used as an additive for water retention, which has a commercial name "WALOCEL MKX 25000 PF 25 L", the manufacturer Dow Chemical Company from the United States. Technical characteristics are shown in Table 7 [10].
Table 7: Technical characteristics „WALOCEL-a MKX 25000 PF 25 L" [10].

\begin{tabular}{|c|c|}
\hline Form & Powder \\
\hline Solubility & Solubility in water \\
\hline Viscosity (2 \% solution), $\mathrm{mPa} \cdot \mathrm{s}$ & $22000-28000$ \\
\hline $\mathrm{pH}$ value & Neutral \\
\hline Moisture content, max.\% & 7 \\
\hline
\end{tabular}

Testing the performance of adhesives, depending on the share of redispersed polymer

Testing the Consistency of Fresh Adhesive: Method of tablequake is used to test the consistency of fresh adhesive. Dry adhesive was prepared by homogenizing the components whose concentrations are given in Table 8. The amount of water was added in the dry adhesive, recommended by the manufacturer, which is enough for the adhesive to be unhindered processed. In the preparation of fresh adhesive in practical part of this paper, $680 \mathrm{ml}$ of water was added to $2 \mathrm{~kg}$ of samples. A moving table consists of round, graduated glass plate. Turning the handle, which is on the side, causes the rising of plate and at one point plate is dropped and causes glue to spread. The following illustration shows moving table with mold on it (Figure 13). In the middle of the board is set mold, whose one third is filled with fresh adhesive. This is followed by 15 taps with a stick (equate occupancy mold). The same is repeated when the two-thirds of the mold are filled and when the entire mold is filled. Then the mold is lifted so that only adhesive remains on the board. The cycles of raising and falling plates are repeated 15 times after what the value of the radius distribution is read off. We read off two radius which are perpendicular to each other. As the result, we take average value. The procedure is repeated three times for each sample. Results of examination are given in Table 9 and Figure 14.

Table 8: Components of dry adhesive and their mass fractions.

\begin{tabular}{|c|c|}
\hline Component & mas. \% \\
\hline Cement & 33,1 \\
\hline Quartz sand & 37,5 \\
\hline Filler (stone dust) & $29,28,27,26$ i 24 \\
\hline Redispersible polymer (RDP) & $0,1,2,3$ i 5 \\
\hline Methyl hydroxy ethyl cellulose (MHEC) & 0,4 \\
\hline
\end{tabular}

Table 9: Results of testing the consistency of fresh adhesive.

\begin{tabular}{|c|c|c|c|c|c|}
\hline $\begin{array}{c}\text { Diameter } \\
\text { (cm) }\end{array}$ & \multicolumn{5}{|c|}{ Share of redispersed polymer [\%] } \\
\hline & 0 & 1 & 2 & 3 & 5 \\
\hline Sample 1 & 17,0 & 17,0 & 17,0 & 17,0 & 17,0 \\
\hline Sample 2 & 16,0 & 17,0 & 17,5 & 17,5 & 18,0 \\
\hline Sample 3 & 18,0 & 18,0 & 17,0 & 17,0 & 17,0 \\
\hline Average & 17,0 & 17,3 & 17,2 & 17,2 & 17,3 \\
\hline
\end{tabular}




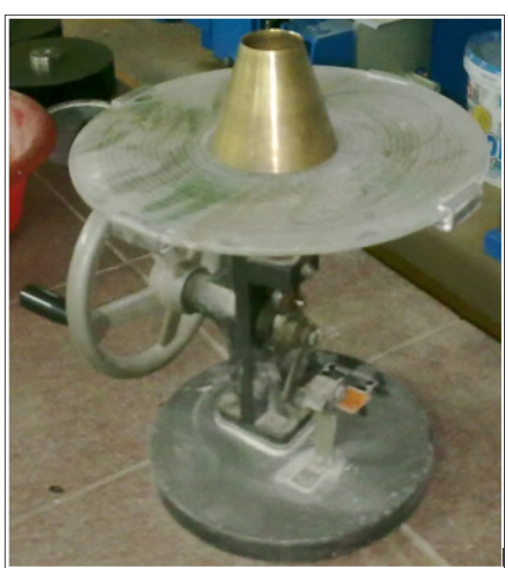

Figure 13: A moving table for testing the consistency of fresh adhesive.

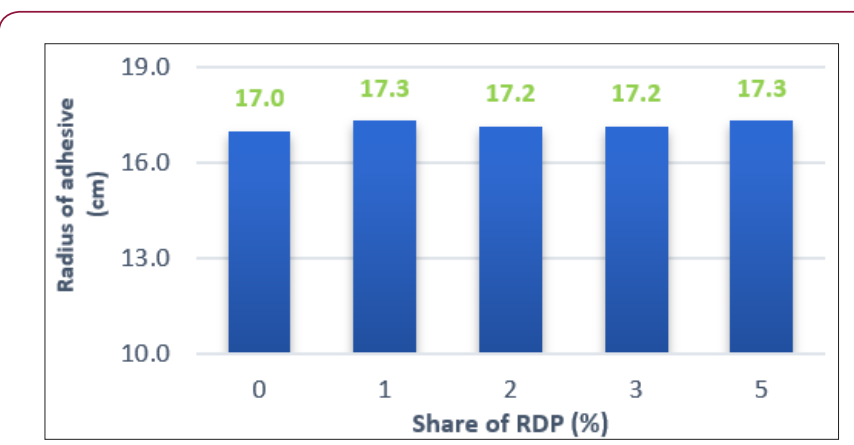

Figure 14: Dependence of consistence of fresh adhesive from the share of redispersible polymer.

On the basis of testing the consistency of fresh adhesive it can be concluded that there is no significant change in consistency along with the increase in the share of dispersed polymer. Consistency of fresh adhesive depends on the friction between the aggregate. If the friction is bigger, consistency is stiff, and vice versa, less friction causes a softer consistency. As the test samples had approximately the same granulometric content, relative humidity of aggregates and the same amount of added water (for making mixtures), this was probably the reason that the consistency was not significantly changed. If the polymer was added in a form of dispersion (liquid form), probably consistency would be softer along with the increasing content of dispersion, because dispersions themselves contain about $50 \%$ water, and also contain surfactants which increase wetting of solid particles.

Adhesion Testing of Adhesive on the Substrate: Adhesion is the interactive force acting between different molecules or different parts of the body. The adhesion of the adhesive to the substrate was investigated as follows: pieces of EPS plates $(10 \times 10 \mathrm{~cm})$ are cut, and then the mixture of fresh adhesive is prepared. After preparation of fresh adhesive, adhesive is applied to the EPS plates, and then placed on substrate. As a substrate used concrete slab, size $30 \times 30 \mathrm{~cm}$. Before placing the EPS plates on the substrate, it is necessary to put two thin ropes between the substrate and the EPS plates. When adhesive is hardened, the concrete slab is turned upside down, and the ropes are fastened to container into which the sand is gradually poured. At one point, as a result of the load, there will be a separation of EPS plate from the substrate, and when that happens we measure the mass of the container with sand. After that, a simple calculation reveals adhesion in

$$
\begin{gathered}
\text { Kpa }: F=m \cdot g \\
\text { Adhesion }=[k P a]=\frac{F}{A} \cdot 1000
\end{gathered}
$$

A-area of EPS plate $\left[\mathrm{mm}^{2}\right] ; A=10000 \mathrm{~mm}^{2}$

Tests were done after 7 days and after 28 days. The results are given in Tables 10 and 11, and in Figures 14 and 15. Comparison of adhesion after 7 and 28 days is given in Figure 16. The results show that the adhesion increases afret seven days along with increasing share of dispersed polymer (almost linear). It also shows the results of the adhesion after 28 days. This increase in adhesion can be explained by the mechanical connection ("jam") polymer in a rough surface (concrete and expanded polystyrene). The values of adhesion after 7 days are slightly less than the value obtained after 28 days. The reason for this behavior is in the process of cement hydration. Cement fully hydrated after 28 days, so that after this period cement achieved the maximum of its mechanical properties, and this is probably the reason of higher value of adhesion for the substrate samples of 28 days from samples of 7 days (Figure 17).

Table 10: Adhesion testing of adhesive on the substrate after 7 days.

\begin{tabular}{|c|c|c|c|c|c|}
\hline $\begin{array}{c}\text { Measurment } \\
\text { values (kPa) }\end{array}$ & \multicolumn{5}{|c|}{ Share of redispersed polymer [\%] } \\
\hline & 0 & 1 & 2 & 3 & 5 \\
\hline Sample 1 & 9,3 & 13,3 & 16,1 & 20,2 & 24,5 \\
\hline Sample 2 & 11,9 & 15,7 & 14,3 & 22,4 & 21,4 \\
\hline Sample 3 & 9,7 & 13,6 & 15,8 & 17,9 & 22,2 \\
\hline Average & 10,3 & 14,2 & 15,4 & 20,8 & 22,7 \\
\hline
\end{tabular}

Table 11: Adhesion testing of adhesive on the substrate after 28 days.

\begin{tabular}{|c|c|c|c|c|c|}
\hline $\begin{array}{c}\text { Measurment } \\
\text { values (kPa) }\end{array}$ & \multicolumn{5}{|c|}{ Share of redispersed polymer [\%] } \\
\hline & 0 & 1 & 2 & 3 & 5 \\
\hline Sample 1 & 10,5 & 16,3 & 18,7 & 23,6 & 29,5 \\
\hline Sample 2 & 12,9 & 14,7 & 22,3 & 25,8 & 26,1 \\
\hline Average & 11,7 & 15,5 & 20,5 & 24,7 & 27,8 \\
\hline
\end{tabular}

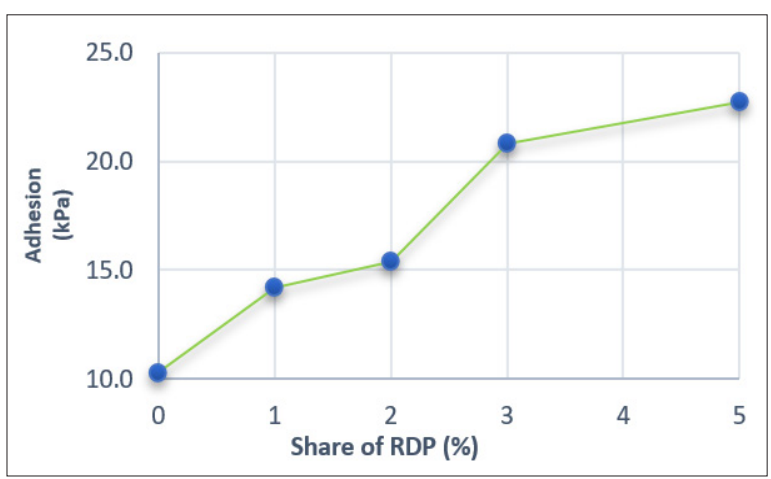

Figure 15: Adhesion of adhesive to the substrate depending on the share of the RDP after 7 days. 


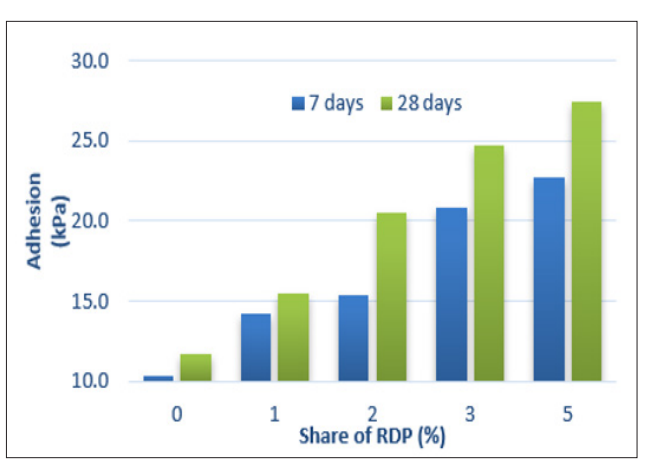

Figure 16: Comparison of adhesion after 7 and 28 days.

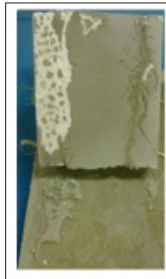

O\% RDP

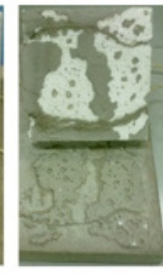

1\% RDP

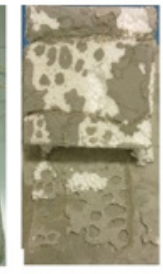

2\%6 RDP

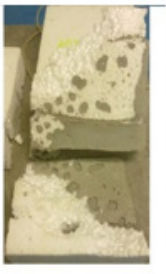

3\% ROP
5\% RDP

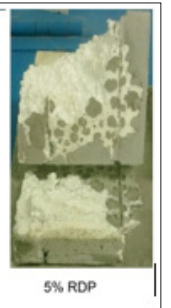

Figure 17: Plates separated from the substrate during the adhesion test.

Figure 17 shows that the plate glued with adhesive with $0 \%$ of RDP is completely separated from the substrate, together with most of adhesive. In the case with the plate which is glued with adhesive with $1 \%$ of RDP, a plate is completely separated from the substrate, but most of the adhesive stayed glued to the substrate. The panel, which is glued with adhesive with $2 \%$ of RDP is not completely separated from the substrate, but a small part stayed attached to the surface. The plates glued with adhesives consisting of $3 \%$ and $5 \%$ of the RDP mainly stayed glued on the substrate, only a small part is separated from the substrate. This shows that the adhesion of adhesive to the surface increases with increasing share of RDP. The polymer bonds that were formed inside the cement matrix additionally link adhesive to surface as well as to EPS plate. Polymer bonds prevents complete separation of EPS plate from the substrate.

\section{Testing Flexural and Compressive Strength of Hardened}

\section{Adhesive}

Sample Preparation of Hardened Adhesive: Table 8. shows the mass percentages of the components of which we have made samples. Testing flexural and compressive strength is done according to the EN 1015-11 standard. Three samples from each glue are prepared, samples' dimensions are $40 \times 40 \times 160 \mathrm{~mm}$. Mold for the production of test samples is shown in Figure 18. Fresh adhesive is brought into the mold in three layers of equal height. After bringing each layer into the mold, the mass is compacted by a metal part of mold. After the mold is filled with fresh adhesive, it is placed in a polyethylene bag and kept there for 24 hours. After 24 hours, if the adhesive is enough harden to be able to remove the samples without damage, the mold will be disassemble and the samples will be taken out. If the adhesive is not harden enough for 24 hours, the samples will be taken out after 48 hours. After that, samples are removed from the mold, and placed in polyethylene bags well tied, so that moisture cannot go into the atmosphere. Otherwise, samples should be cherish in the water, because the main binder is a cement for whose hydration the water is necessary, however, water completely counteracts the effects of RDP on adhesive properties, so samples are kept in polyethylene bags, which retain the moisture required for the hydration of cement, and in addition there will be no negative effect on the RDP.

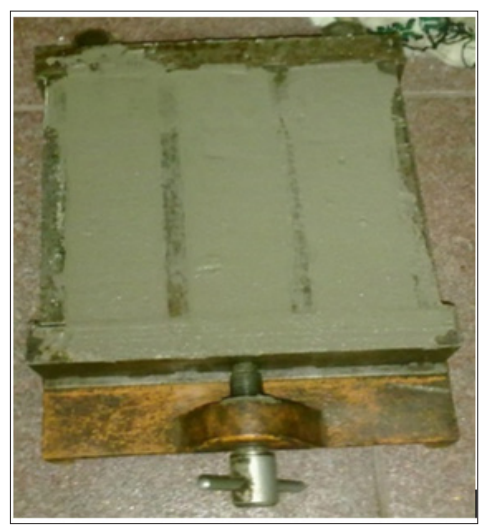

Figure 18: The mold filled with fresh adhesive.

Testing Flexural Strength of Hardened Glue: Flexural strength is the ability of material to resist deformation caused by load. To determine the flexural strength, we tested three prisms with the dimensions $40 \times 40 \times 160 \mathrm{~mm}$. Prism is laid against two cylindrical supports. Concentrated forces act in the middle of the sample, as shown in Figure 19. The intensity of the force is increased till the sample gets broken. Tests are performed using Michaelis press (Figure 20) [11]F. Flexural strength is calculated by the following formula:

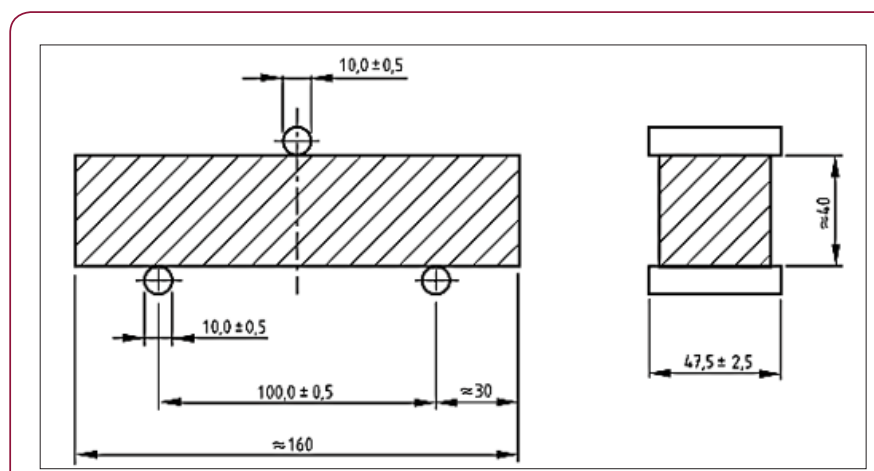

Figure 19: Testing flexural strength of hardened adhesive [11].

$$
f=1,5 \frac{F l}{b d^{2}}(8)
$$

where is:

f- flexural strength, $\mathrm{N} / \mathrm{mm}^{2}$,

F- the maximum force acting on the sample, $\mathrm{N}$,

l- wheelbase, mm,

b- width of sample, mm; d - the height of sample, mm. 


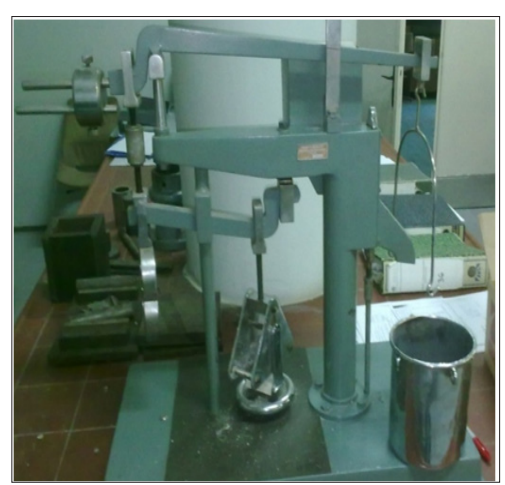

Figure 20: Michaelis press. $\mathrm{f}_{2} \mathrm{if}_{3}$.

Relevant result is the average value of three measurements $f_{1}$,

$$
f_{s}=\frac{f_{1}+f_{2}+f_{3}}{3}
$$

Results of testing are given in Table 12 and Figure 21.

Table 12: Value measurement of flexural strength of hardened adhesive.

\begin{tabular}{|c|c|c|c|c|c|}
\hline $\begin{array}{c}\text { Measurment } \\
\text { values (MPa) }\end{array}$ & \multicolumn{5}{|c|}{ Share of redispersible polymer [\%] } \\
\hline & 0 & 1 & 2 & 3 & 5 \\
\hline Sample 1 & 1,79 & 1,56 & 1,48 & 1,33 & 1,11 \\
\hline Sample 2 & 1,81 & 1,52 & 1,52 & 1,38 & 1,15 \\
\hline Sample 3 & 1,80 & 1,50 & 1,44 & 1,36 & 1,12 \\
\hline Average & 1,80 & 1,53 & 1,48 & 1,36 & 1,13 \\
\hline
\end{tabular}

\begin{tabular}{|l|l|l|l|l|}
\hline & 2.00 & & & \\
\hline
\end{tabular}

Figure 21: The dependence of the flexural strength of the hardened adhesive in relation to a share of RDP.

The results shown that there has been a decrease of flexural strength with increasing the share of redispersed polymer (Table 12). Redispersible polymer, used in test, has a low glass transition temperature $\left(-6^{\circ} \mathrm{C}\right)$, and belongs to soft redispersed polymers, so that it assigns the same properties to the material, ie. adhesive becomes more elastic, softer, so that, under the load on Michaelis press flexing and cracking of sample occur. This is probably reason why there has been a decrease of flexural strength with the increase in the share of redispersed polymer.

Testing Compressive Strength of the Hardened Adhesive: Compressive strength is the maximum pressure that adhesive can bear without breakage or cracking [12]. This test is performed on samples subjected to previous testing of flaxural strength. Each half of the sample is exposed to gradual load, perpendicular to the direction of compaction when creating samples. Hydraulic press is used for this experiment, for testing compressive strength. The pressure acting on the area of $4 \times 4 \mathrm{~cm}$. Test results are provided in Table 13 and Figure 22. The results show that the compressive strength of hardened adhesive decreases along with the increase of the share of redispersed polymer, as well as flexural strength do. The reason for this behavior is the same as in flexural strength, ie. type of redispersible polymer belongs to the soft types of redisperse polymer because of the low glass transition temperature $\left(-6^{\circ} \mathrm{C}\right)$, so to say, because of the allocation of the same properties, ie. becomes softer and more elastic, and therefore the compressive strength decreases.

Table 13: Measuring values of compressive strength of hardened adhesive.

\begin{tabular}{|c|c|c|c|c|c|}
\hline $\begin{array}{c}\text { Measurment } \\
\text { values (MPa) }\end{array}$ & \multicolumn{5}{|c|}{ Share of redispersible polymer [\%] } \\
\hline & 0 & 1 & 2 & 3 & 5 \\
\hline Sample 1 & 2,86 & 2,38 & 2,10 & 1,84 & 1,49 \\
\hline Sample 2 & 3,33 & 2,85 & 2,23 & 1,87 & 1,74 \\
\hline Sample 3 & 3,11 & 2,60 & 2,09 & 1,99 & 1,78 \\
\hline Average & 3,10 & 2,61 & 2,14 & 1,90 & 1,67 \\
\hline
\end{tabular}

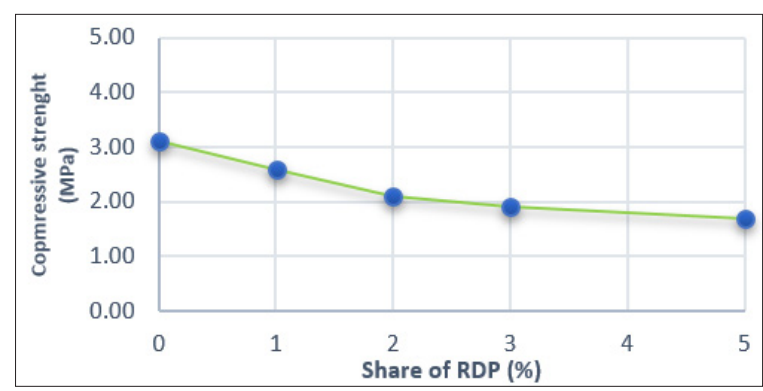

Figure 22: Compressive strength of hardened glue in relation to the share of RDP.

Testing Capillary Water Absorption, the Hardened Adhesive: Testing capillary absorption of the hardened adhesive is being tested on parts of samples that had previously been subjected to the test of flexural strength. Testing is done according to standard EN 1015-18. The longer sides of the samples are first painted over with paraffin wax or a synthetic resin, and then dried in an oven to constant weight. Figure 23 shows the samples immersed in water. The samples are set up in such a way that the broken part faces the ground. Samples are placed on a small support (supports should have little surface), and then water is poured into the container, so that 5-10 mm of samples are immersed in water. Time of samples immersion is recorded. Mass measurement is tested after 10 and after 90 minutes. Samples are removed from the water, and residual water on the samples is removed with a cloth, and then the weight of samples is measured. Test results are given in Tables $14 \& 15$ and Figures $24 \& 25$ The results shown that the capillary water absorption of the hardened glue decreased with increasing share of redispersed polymer. This decrease in capillary water absorption is explained by filling the pores with coagulated polymer, reducing 
the open porosity and slowing the development of micro cracks. So, by increasing the content of the RDP, there will be a better filling of pores in the cement matrix with polymer material and therefore it will reduce water penetration into the material.

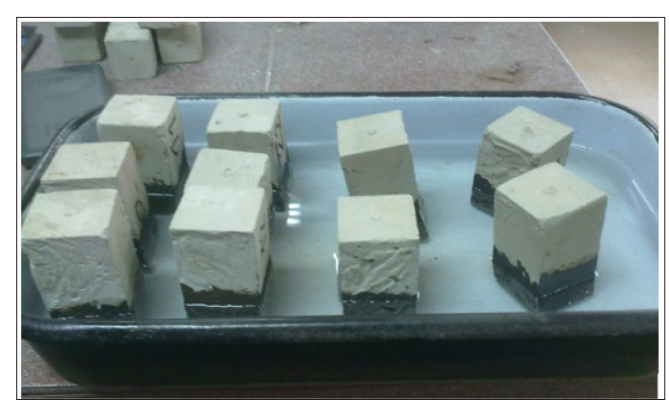

Figure 23: Samples for testing of capillary water absorption of hardened adhesive.

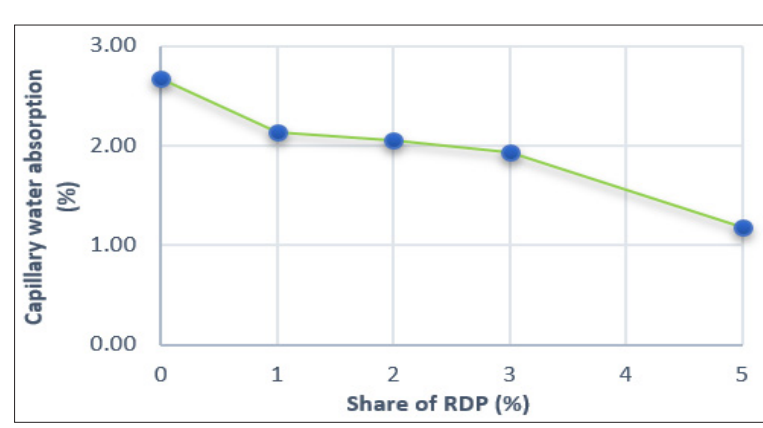

Figure 24: Dependence of the capillary water absorption of hardened adhesive from share RDP after 10 minutes.

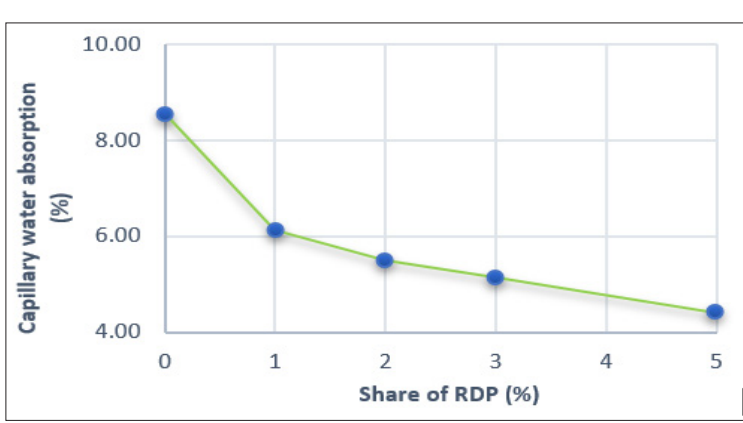

Figure 25: Dependence of the capillary water absorption of hardened adhesive from share RDP after 90 minutes.

Table 14: Measurement values of capillary water absorption of hardened adhesive after 10 minutes - experiment results.

\begin{tabular}{|c|c|c|c|c|c|}
\hline $\begin{array}{c}\text { Measurment } \\
\text { values (MPa) }\end{array}$ & \multicolumn{5}{|c|}{ Share of redispersible polymer [\%] } \\
\hline & 0 & 1 & 2 & 3 & 5 \\
\hline Sample 1 & 2,67 & 2,19 & 2,05 & 1,98 & 1,17 \\
\hline Sample 2 & 2,68 & 2,09 & 2,08 & 1,95 & 1,23 \\
\hline Sample 3 & 2,65 & 2,15 & 2,03 & 1,90 & 1,15 \\
\hline Average & 2,67 & 2,14 & 2,05 & 1,94 & 1,18 \\
\hline
\end{tabular}

Table 15: Measurement values of capillary water absorption of hardened adhesive after 90 minutes experiment results.

\begin{tabular}{|c|c|c|c|c|c|}
\hline $\begin{array}{c}\text { Measurment } \\
\text { values (MPa) }\end{array}$ & \multicolumn{5}{|c|}{ Share of redispersible polymer [\%] } \\
\hline & 0 & 1 & 2 & 3 & 5 \\
\hline Sample 1 & 9,11 & 6,16 & 5,50 & 5,23 & 4,36 \\
\hline Sample 2 & 8,16 & 6,04 & 5,43 & 5,14 & 4,45 \\
\hline Sample 3 & 8,38 & 6,20 & 5,58 & 5,05 & 4,41 \\
\hline Average & 8,55 & 6,13 & 5,50 & 5,14 & 4,41 \\
\hline
\end{tabular}

Testing Volume Mass of Hardened Adhesive: Volume of hardened adhesive is the ratio of mass and volume of the hardened adhesive together with cavities and pores. It is expressed in $\mathrm{kg} / \mathrm{m}^{3}$. The sample has dimensions of $40 \times 40 \times 160 \mathrm{~mm}$ and is prepared according to BS EN 1015-11 standard. Hardened samples are dried to constant weight and then weighed. The volume of the sample is known, so that the volume mass is calculated by the formula.

$$
\text { Volume mass of hardened adhesive }=\frac{\text { mass of hardened adhesive }}{\text { volume of hardened adhesive }}
$$

Table 16 shows the values of volume mass of adhesive depending on the content of the RDP, the results are also presented in Figure 26. From the results it can be seen that the increase in the share of redispersed polymer causes decrease in volume mass of hardened adhesive. It is logical order to maintain the mass balance of the recipe: if we increase the proportion of RDP in the mixture, the proportion of other components will be reduce by the same percentage [13]. In this case the component which is decreased share in the mixture is stone dust (filler), which has higher specific gravity than the specific weight of the RDP, so that it is reflected on the volume weight of hardened adhesive [14-15].

Table 16: Measurment values of volume mass of adhesive depending on the share of RDP - experiment results.

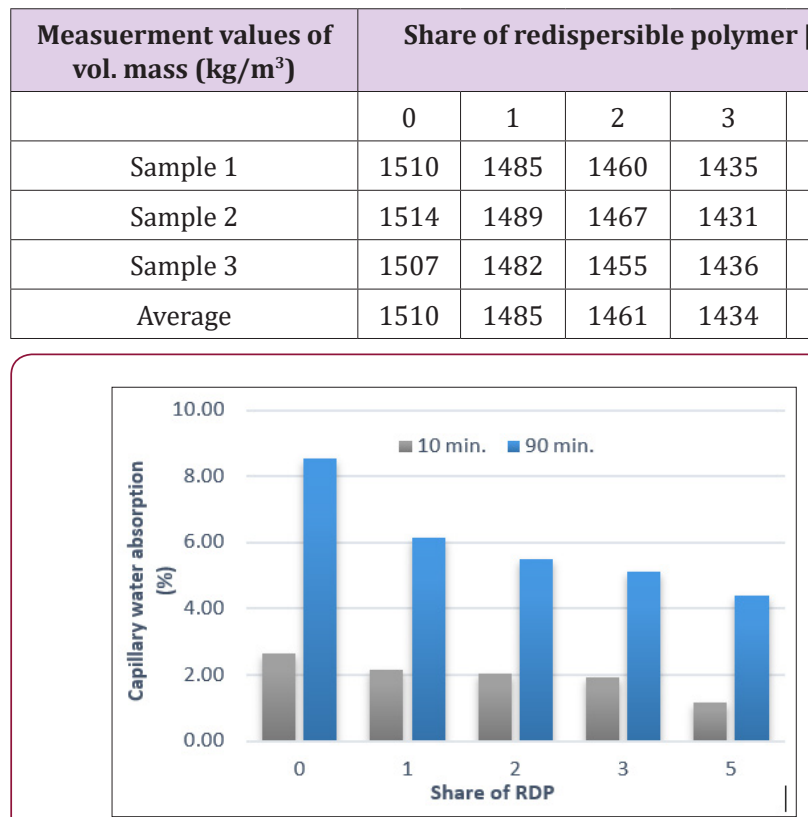

Figure 26: Comparison of capillary water absorptions after 10 and after 90 minutes. 


\section{Conclusion}

The results of tests carried out in the context of practical part show that the addition of the redispersed polymer directly affects all investigated properties, except the consistency of fresh adhesive where there have been no significant changes with increase of the share of redispersed polymer. The adhesion of adhesive on the surface is increased with the increase of the share of redispersed polymer, because of the occurrence of formation of polymer bond in the cement matrix that additionally binds adhesive on substrate. Adhesion is also the main characteristic of adhesives for external thermal insulation together with the capillary water absorption, so that the redispersed polymer is added in order to increase adhesion of mortar of the substrate and to reduce the capillary water absorption.

The results show decrease of the flexural and compressive strength of the adhesive with the increasing share of redispersed polymer, because of the type of the redispersed polymer used, ie. redispersible polymer used belongs to the class of redisperse soft polymers because of the low glass transition temperature $\left(-6^{\circ} \mathrm{C}\right)$. Increase of the share of dispersed polymer leads to decrease of volume mass, primarily because of reduced share of aggregate which has higher specific weight than the specific weight of the polymer dispersion. In practice, we add 1 to 35 of the redispersion polymer. We add 1 to $2 \%$ of redispersible polymer in the adhesive for gluing EPS panels, while the adhesive for the reinforcement contains 2 to $3 \%$. It should be noted that the redispersion polymers are most expensive components in adhesives for external thermal insulation, so that with these proportions satisfactory properties of adhesive are achieved and by this competitive product is provided.

\section{References}

1. Josef K Felixberger (2008) polymer-modified thin-bed tile adhesives.

2. www.exco.hr

3. http://www.exco.hr/eaadmin/catpics/J30_1_E_1.pdf

4. www.sesam-uae.com

5. http://www.sesam-uae.com/green/seminar0608/press/Wacker\%20 Chemicals.pdf

6. P Petrovski, I Bušatlić (2006) cementi i druga neorganska mineralna veziva, Univerzitet u Zenici, Zenica.

7. M Muravljov (2000) Građevinski Materijali, Građevinska knjiga, Beograd.

8. www.univareurope.com

9. http://www.univareurope.com/uploads/documents/uk/Dow_Powder_ Polymers.pdf

10. P Krolo (1999) Tehnologija Veziva I Kompozitnih Materijala, Sveučilište U Splitu, Split.

11. E Aganović (2003) kvalitativna i kvantitativna mineraloška analiza portland cementa metodom rendgenske spektrofotometrije, Diplomski rad, Univerzitet u Zenici, Zenica.

12. www.vinavil.comhttp://www.vinavil.com/public/1/SchedeTecniche/ EN_VINAVIL5603PB.pdf

13.w ww.dowconstruction chemicals.com http: / / w w w. dowconstructionchemicals.com/na/en/pdfs/832-00067.pdf

14. BS EN (2005) methods of testing mortar-determinaton of strength, London, Uk, pp. 196-191.

15. BS EN (1999) methods of test for mortar for masonry-determination of flexural and compressive strength of hardened mortar, London, UK, pp. 1015-1011.

\section{ISSN: 2574-1241}

DOI: 10.26717/BJSTR.2018.11.002087

Krdžalić Edin. Biomed J Sci \& Tech Res

CC (P) This work is licensed under Creative

Submission Link: https://biomedres.us/submit-manuscript.php

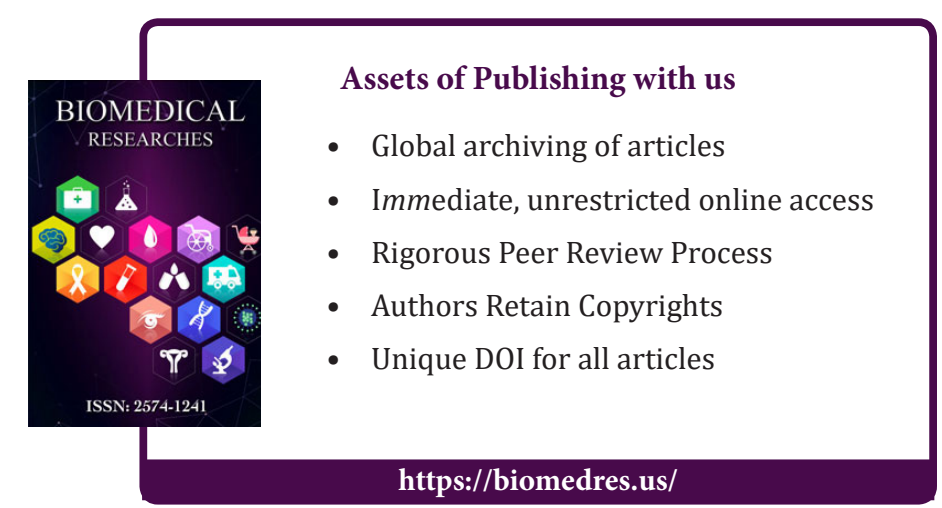

